\title{
Combining satellite radar altimetry, SAR surface soil moisture and GRACE total storage changes for hydrological model calibration in a large poorly gauged catchment
}

\author{
C. Milzow ${ }^{1}$, P. E. Krogh ${ }^{2}$, and P. Bauer-Gottwein ${ }^{1}$ \\ ${ }^{1}$ Department of Environmental Engineering, Technical University of Denmark, 2800 Kgs. Lyngby, Denmark \\ ${ }^{2}$ National Space Institute, Technical University of Denmark, 2100 Copenhagen, Denmark
}

Received: 12 November 2010 - Published in Hydrol. Earth Syst. Sci. Discuss.: 30 November 2010

Revised: 30 April 2011 - Accepted: 11 May 2011 - Published: 6 June 2011

\begin{abstract}
The availability of data is a major challenge for hydrological modelling in large parts of the world. Remote sensing data can be exploited to improve models of ungauged or poorly gauged catchments. In this study we combine three datasets for calibration of a rainfall-runoff model of the poorly gauged Okavango catchment in Southern Africa: (i) surface soil moisture (SSM) estimates derived from radar measurements onboard the Envisat satellite; (ii) radar altimetry measurements by Envisat providing river stages in the tributaries of the Okavango catchment, down to a minimum river width of about one hundred meters; and (iii) temporal changes of the Earth's gravity field recorded by the Gravity Recovery and Climate Experiment (GRACE) caused by total water storage changes in the catchment. The SSM data are shown to be helpful in identifying periods with overrespectively underestimation of the precipitation input. The accuracy of the radar altimetry data is validated on gauged subbasins of the catchment and altimetry data of an ungauged subbasin is used for model calibration. The radar altimetry data are important to condition model parameters related to channel morphology such as Manning's roughness. GRACE data are used to validate the model and to condition model parameters related to various storage compartments in the hydrological model (e.g. soil, groundwater, bank storage etc.). As precipitation input the FEWS-Net RFE, TRMM 3B42 and ECMWF ERA-Interim datasets are considered and compared.
\end{abstract}

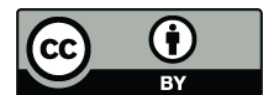

Correspondence to: C. Milzow (christian.milzow@alumni.ethz.ch)

\section{Introduction}

Hydrological modelling faces the challenge of decreasing availability of in-situ monitoring data. Worldwide, the number of meteorological stations as well as the number of operational discharge monitoring stations has been decreasing continuously since the 1970s (Fekete and Vörösmarty, 2007; Jones and Moberg, 2003; Peterson and Vose, 1997). Whereas data from such stations are vital for the calibration and validation of hydrological models, many major river basins of the world are currently poorly monitored.

Satellite based remote sensing provides valuable data for hydrological model calibration and validation. Over the last decades the availability of remote sensing data has increased; many hydrological state variables and water fluxes can now be assessed remotely through indirect measurements. Outgoing solar radiation is for example related to surface and cloud temperature and is measured for evapotranspiration and precipitation calculations. The travel time of a radar signal between a satellite and a water surface is related to the water level elevation. These indirect measurements bring additional sources of uncertainty that are often related to the unknown exact conditions of the atmosphere. Precipitation, evapotranspiration, surface soil moisture, total terrestrial water storage variations, river and lake levels have all been studied through remote measurements (see Tang et al., 2009, for a review). In this study we use remotely sensed datasets of precipitation, surface soil moisture, river stages and total water storage for a hydrological model of a poorly gauged basin - the Okavango basin in Southern Africa.

Soil moisture influences the microwave backscattering characteristics of the earth surface. This effect can be used to

Published by Copernicus Publications on behalf of the European Geosciences Union. 
estimate the surface soil moisture (SSM) based on satellite radar measurements. For the Okavango catchment, a good correlation with a lag of three months between SSM data and catchment outflow was observed by Bartsch et al. (2008). Studies using SSM data have also been published on the neighbouring Zambezi catchment. A high correlation was found in the Zambezi between soil moisture and runoff by Scipal et al. (2005) and was recently exploited for real-time hydrological modelling by Meier et al. (2011). The study by Parajka et al. (2006) revealed no improvement of runoff simulations by assimilating SSM data into a model for ungauged catchments in Austria. However, Crow and Ryu (2009) showed for basins of the United States that assimilation of SSM data can correct for errors in the precipitation input and thus improve runoff simulations.

Water levels in rivers and lakes can be monitored by satellite altimeters although these instruments have until now never been specifically designed for continental hydrological applications. Calmant et al. (2008) give a review of the processing technique and the available databases. The accuracy of the retrieved water levels strongly depends on site characteristics. The wider the river, the better is the accuracy. For smaller rivers, radar returns from off-nadir locations can seriously affect the accuracy. Continental applications of altimetry data have therefore so far been limited to lakes (e.g. Birkett and Beckley, 2010; Sarmiento and Khan, 2010; Becker et al., 2010) and large river systems as for example the River $\mathrm{Ob}$ (Kouraev et al., 2004), the Amazon (Coe et al., 2008) and the Mekong (Birkinshaw et al., 2010).

The total water storage change in a catchment locally influences the time variation of the gravitational field of the earth. This can be used to derive storage changes trough time-lapse gravimetric measurements. In-situ gravimetric measurements are not suited for studies at the catchment scale because the footprint of ground-based gravimeters is on the order of several tens of meters (Leiriao et al., 2009). The Gravity Recovery and Climate Experiment (GRACE) has been monitoring temporal changes in the earth's gravity field since 2002 (Tapley et al., 2004). GRACE recovers global and local gravity fields from the inter-satellite rangerate measurements in-between its twin-satellites. Tidal and atmospheric effects are removed by forward models, so that in the absence of tectonic movements, changes in the gravitational field are dominated by changes in water storage at the land surface. With a maximal spatial resolution of $400 \mathrm{~km}$, GRACE data can be used exclusively in large river catchments. GRACE data have been used for numerous studies of large river basins worldwide. Recent application include for instance the Amazon (Chen et al., 2010), the MurrayDarling (Awange et al., 2011) and the Eurasian pan-Arctic region (Landerer et al., 2010). Grace data have been used for model calibration by Lo et al. (2010) in North America. Moiwo et al. (2009) have identified storage depletion in the Hai River basin in northern China using GRACE data. Pfeffer et al. (2011) removed large scale gravity variations measured by GRACE for a local study in Niger with in-situ gravity measurements.

The challenge is to integrate these diverse datasets to improve the parametrization of hydrological models. Automatic multi-objective model calibration that minimizes the deviations between the different observed and simulated time series can be used for this purpose. Such a procedure will ensure that all available observations are accounted for and given a defined weight when identifying the optimal set of parameter values. In contrast to data assimilation techniques, we do not use the remotely sensed data to modify the states or parameters of our model at discrete time steps. We apply the remotely sensed data to identify an optimal set of parameters that is constant in time and gives a simulation of model states without discontinuities.

The model development presented in this article is part of a larger project in which the model will serve as a tool to assess the impact of agricultural development in the Okavango basin. The model will be applied conjunctively with an existing model of the downstream Okavango Delta wetlands (Milzow et al., 2009b, 2010) to study the impact of agricultural development in the catchment on the hydrology and ecology of the Okavango Delta. This final application to be presented in a future publication justifies the choice of a complex precipitation-runoff model that includes a detailed simulation of vegetation processes.

\section{Materials and methods}

\subsection{Study area}

The Okavango River (Fig. 1) - which includes portions of Angola, Namibia and Botswana - is representative for many large rivers throughout the developing world in that it is poorly gauged and studied. The two main tributaries of the Okavango River arise in the southern highlands of Angola. They join on the border to Namibia before the river crosses the $30 \mathrm{~km}$ wide Caprivi-Strip. The lowest part of the basin consists of the large Okavango Delta wetlands on Botswana territory. The wetlands constitute a biodiversity hotspot of global importance (Junk et al., 2006; Ramberg et al., 2006) and, through tourism, an important source of economic income for Botswana (Mmopelwa and Blignaut, 2006). The catchment area upstream of the wetlands is of approximately $170000 \mathrm{~km}^{2}$. Non-runoff-generating parts of the basin extend over an additional $220000 \mathrm{~km}^{2}$ into Namibia and Botswana.

At present, the Okavango catchment is largely ungauged. No current in-situ precipitation measurements are available for the Angolan part of the catchment where most runoff is generated. An operational precipitation gauge is located at Rundu in the most southern and driest part of the catchment. Historic precipitation data for the period from 1954 to 1984 are available from 12 stations distributed over the 


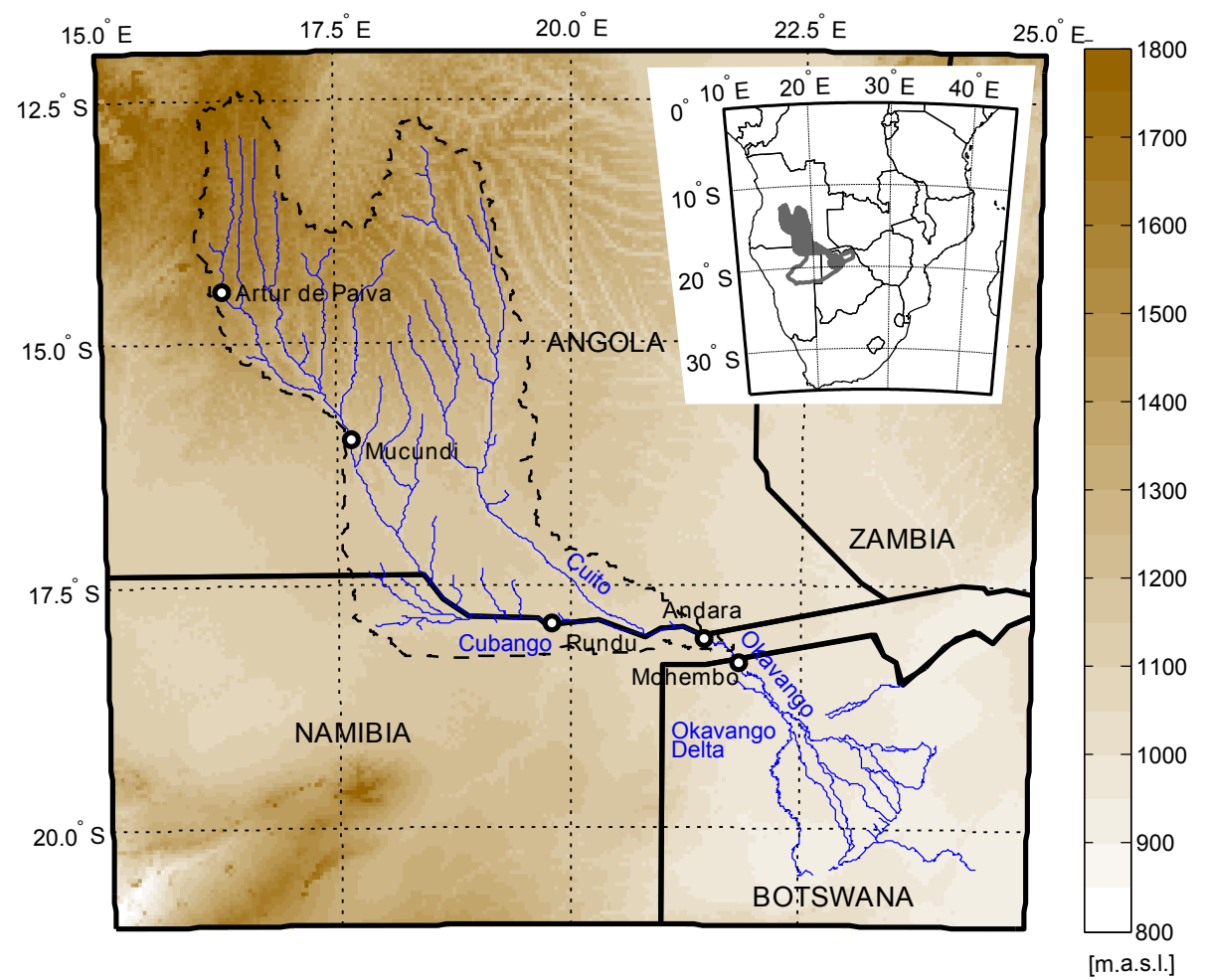

Fig. 1. The Okavango River Basin. The inset shows Southern Africa with the active (filled area) and non-active (outline) parts of the Okavango Basin.

catchment (Nicholson and Entekhabi, 1986). These records have monthly time resolution and differ in length for the individual stations. River discharge and stage are presently monitored only at the outlet of one of the two main subbasins and in the main Okavango River before it flows into the Okavango Delta wetlands (Rundu, Andara and Mohembo, see Fig. 1). Monthly discharge data has been recorded at 14 additional stations within the catchment for time spans of variable length in the period from 1957 to 1974 (see Hughes et al., 2006, for details).

Very few studies have been published on the Okavango catchment. This lack of attention contrasts with the large number of studies on the downstream part of the basin, the Okavango Delta (see Milzow et al., 2009a, for a review). However, scientific interest in the catchment is slowly growing. Kgathi et al. (2006); Mendelson and el Obeid (2004) give overviews of geographical and social aspects of the catchment. Andersson (2006) studied the land cover change during the Angolan civil war using satellite imagery. $\mathrm{He}$ identified decreases of NDVI (normalized difference vegetation index) in the northwest and increases in the northeast. $\mathrm{He}$ was unable to rule out that these changes were related to precipitation differences between the years. He finds that from 1973 to 2001 the area used for large scale agriculture increased from 44 to $70 \mathrm{~km}^{2}$.
Two hydrological models of the catchment have been reported in literature, both having the objective to study the impact of climate change and development on hydrology. The model by Folwell and Farqhuarson (2006) is based on the Global Water AVailability Assessment model (GWAVA) and can be applied to study the impact of changes in climate and water demand. It can however not predict changes in water demand based on land use changes. A second conceptual rainfall-runoff model with monthly time step was developed for the Okavango catchment by Hughes et al. (2006, 2011) based on the Pitman model. Both models achieve a satisfactory fit of the observed discharges but are insufficient in terms of simulated processes to be applied in the present project. Because our final goal is to simulate impacts of land use changes, we opted for a model with daily time step and a more physically-based representation of especially the soil layer.

Both reported models cover the period from 1961 to 1990 whereas our model uses input data available since 1998. A direct comparison with our model for the early period is therefore not possible. However, the input data used in the model by Hughes et al. $(2006,2011)$ is now available until 2008 such that a comparison for the period 1998 to 2008 would be possible. Hughes et al. $(2006,2011)$ find that different precipitation datasets result in very variable model performance. This is confirmed in our study. A model 
comparison might therefore indicate differences in the input data rather than in model performance.

\subsection{Remotely sensed input and calibration data}

Three operational precipitation products covering the Okavango catchment are available. The Tropical Rainfall Measuring Mission (TRMM) provides data from 1998 onwards. We use the 3B42 product, which has a temporal resolution of three hours and a spatial resolution of $0.25^{\circ}$. The principal components of the mission are a precipitation radar, a passive microwave imager and a visible and infrared scanner (Adler et al., 2007). A time series of similar length, higher spatial but lower temporal resolution is the rainfall estimates product (RFE) available through the Famine Early Warning Systems Network (FEWS-Net) which was launched in 1995. RFE is based on Meteosat infrared images and microwave satellite observations (Herman et al., 1997). The temporal resolution of this dataset is 1 day (10 days before 1998) and the spatial resolution is $8 \mathrm{~km}$. TRMM and FEWS-Net data both incorporate ground station precipitation data, where available.

An alternative source for precipitation data, and a source for temperature data, is the ERA-Interim reanalysis of the European Centre for Medium-Range Weather Forecasts (Berrisford et al., 2009). It is produced by near real time modelling of the global circulation with assimilation of large amounts of observations. ERA-Interim data is publicly available with a spatial resolution of $1.5^{\circ}$ and a temporal resolution of $6 \mathrm{~h}$. The ERA-Interim product is available since 1989 but an earlier version, ERA-40, with a spatial resolution of $2.5^{\circ}$ is available since 1957 .

The SHARE project, Technical University of Vienna, provides SSM estimates at $1 \mathrm{~km}$ resolution for Africa south of $12^{\circ} \mathrm{N}$ and Australia (Bartsch, 2008; Wagner et al., 2007). The acquiring instrument is the advanced synthetic aperture radar (ASAR) onboard Envisat. The SSM estimates represent the top $5 \mathrm{~cm}$ of the soil, approximately, and provide soil moisture relative to the driest and wettest conditions ever observed for each ground point.

The remotely sensed river stages employed are from the River and Lake Altimetry (RLA) product, which is processed at the de Montfort University with altimetry data from the ERS2, Envisat, Jason1 and Jason2 satellites (Berry et al., 2005). For the Okavango River only data from the ERS2 and ENVISAT satellites provide usable water level time series. The temporal resolution is equal to the return period of the satellite, which is 35 days for Envisat.

The time series of total water storage for the Okavango catchment is derived from the GRACE gravity data by using the method of mass concentrations (mascons), which is also used at the NASA/Goddard Space Flight Center (e.g., Luthcke et al., 2008; Rowlands et al., 2010). For more information on the mascon recovery from range-rates (see Krogh, 2011). Range-rate data for recovery of mascons are available from April 2003 to present. Gravity fields were recovered with 10 day intervals.

\subsection{Hydrological modelling concept}

We conduct water balance modelling and stream flow routing using the Soil and Water Assessment Tool, SWAT (Arnold et al., 1998; Neitsch et al., 2005). SWAT is a daily time step, physically based rainfall-runoff model for large river basins. It has been developed for studies of land management impact on stream flow quantity and quality. SWAT includes a vegetation growth component which allows simulating irrigation and fertilizer requirements for cultivated crops. Simulated vegetation growth is driven by water availability, radiation and nutrient availability. SWAT is therefore adequate to study the impact of agricultural intensification in the Okavango catchment. SWAT includes several process parametrization options for hydrological processes such as e.g. surface runoff, flow routing etc. In the following we only discuss the parametrizations used in our model.

The modelled basin is divided into subbasins, which are in turn divided into hydrological response units (HRUs). Individual HRUs of a subbasin have different soil, land use and slope characteristics but are not assigned a specific position within the subbasin. The water balance component of the model takes place at the HRU level. The uppermost simulated component is an interception reservoir, followed by percolation through the soil column or surface runoff. The amount of surface runoff is calculated with the Soil Conservation Service (SCS) curve number procedure (Rallison and Miller, 1981), which accounts for soil type, land use and antecedent moisture conditions. Surface runoff can infiltrate into lower soil layers as bypass flow through cracks if the soil water content of upper layers is below one tenth of the field capacity. Cracks close with rising water content (Neitsch et al., 2005). Lateral flow in each soil layer is calculated based on a kinematic storage model (Neitsch et al., 2005). Potential evapotranspiration is computed using Hargreave's formula, which requires inputs of incoming extraterrestrial solar radiation, minimum and maximum daily temperature. Data required for more elaborate calculations of the potential evapotranspiration (e.g. wind speed, relative humidity) are unavailable for the catchment. HRUs contribute fluxes to a ground water reservoir for each subbasin (percolation through the soil column and the vadose zone) and directly to the stream reach associated with the subbasin (surface flow, lateral flow). Groundwater reservoirs contribute baseflow to the stream depending on a baseflow recession constant that links changes in groundwater recharge to changes in outflow.

Flows are routed through the stream network using the variable storage routing method. Manning's equation is used to calculate flow rates and velocities. Seepage from the river to the groundwater reservoir is simulated depending on flow width and hydraulic conductivities of river beds. A first-order interaction between the river and a bank storage reservoir is 

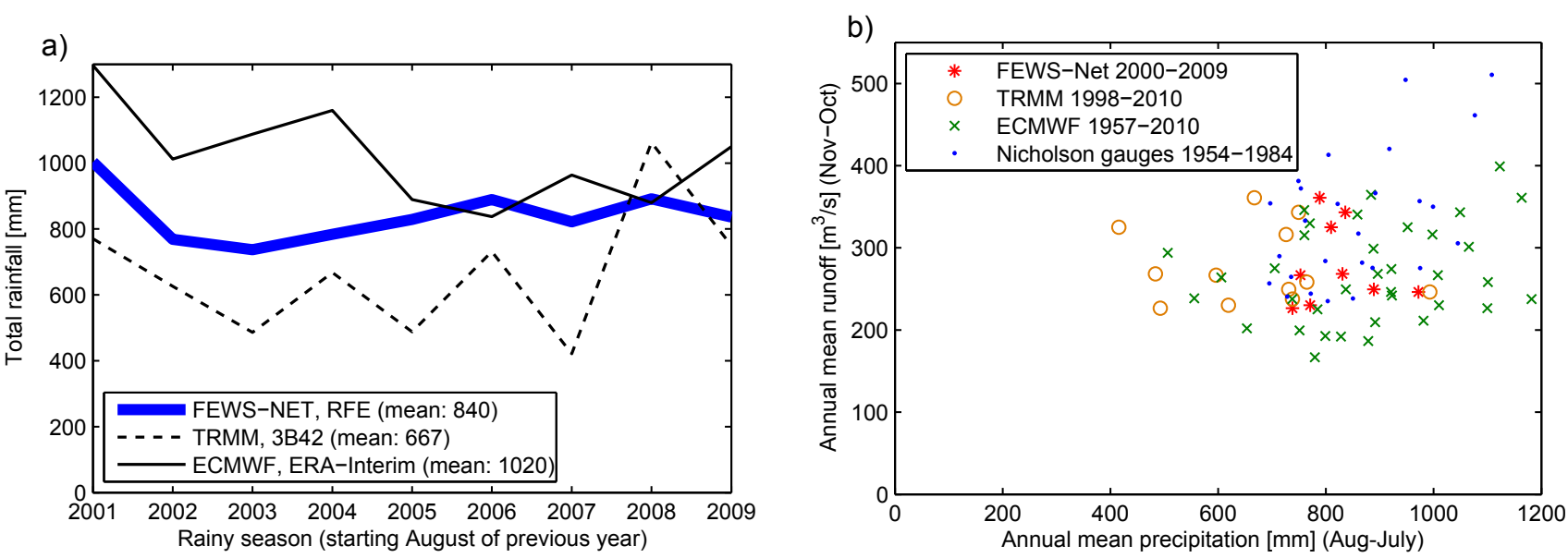

Fig. 2. (a) Annual precipitation sums averaged over the Okavango catchment for three precipitation products. (b) Scatter plot of annual (August to July) precipitation against annual (November to October) discharge for the three used products and earlier in-situ data of the Nicholson database.

further considered for each reach. For this purpose changes to the original SWAT code were implemented. The infiltrating or exfiltrating flux $Q_{\text {filter }}$ is calculated based on the difference in water levels between river and bank storage compartment, $\Delta h$, the leakage factor of the river bed $\lambda_{\text {bed }}$ (equal to the hydraulic conductivity of the river bed divided by its thickness), the wetted perimeter $P_{\text {wet }}$ of the channel cross section, and the length $L$ of the reach.

$Q_{\text {filter }}=-\Delta h \cdot \lambda_{\text {bed }} \cdot P_{\text {wet }} \cdot L$

Evapotranspiration from the bank storage is simulated as in the standard SWAT version.

\subsection{Model setup}

The Okavango catchment is divided into 7 subbasins and a total of 86 HRUs. The scarcity of data available for the catchment area does not support a finer resolution. The stream network is delineated using the ArcSWAT interface (Winchell et al., 2007). ArcSWAT requires solely a digital elevation model for this processing step. We have used the shuttle radar topographic mission data (SRTM, Farr et al., 2007) as input. The general structure of the stream network generated in ArcSWAT corresponds to the observed stream network and is used for the model. The length of all reaches is however corrected because the SRTM topography with its $90 \mathrm{~m}$ resolution is too coarse to reflect the accurate position of meandering streams. A digital stream map is available through the online database of the Sharing Water Project (RAISON, 2004) and was used to calculate accurate reach lengths. The width for every reach is picked from GoogleEarth imagery.

Schuol et al. (2008) have set up a SWAT model for the entire African continent and generated SWAT compatible databases for soil type and land use. These are used in this study. The original data used by Schuol et al. (2008) have global coverage. Land cover characteristics were derived from the $1 \mathrm{~km}$ resolution Global Land Cover Characterization Database of the US Geological Survey (USGS, 2008). Soil parameters were extracted from the 2 layer and $10 \mathrm{~km}$ horizontal resolution digital soil map of the world published by the World Food and Agricultural Organization (FAO, 1995). For the Okavango model the thickness of the upper soil layer is reduced by $5 \mathrm{~cm}$ and a new, $5 \mathrm{~cm}$ thick top layer, is introduced for consistency with the SSM data.

\subsection{Intercomparison of precipitation data}

The three precipitation products described in the introduction (ECMWF ERA-Interim, TRMM 3B42, FEWS-Net RFE) are considered as model inputs. The differences between these datasets are very large for the Okavango catchment (Fig. 2a). Annual sums over the catchment are on average $26 \%$ higher in the FEWS-Net product than in the TRMM product but the latter still gives a higher annual sum for 2008. ERAinterim data provide an average annual sum as much as $53 \%$ higher than TRMM data. Based on earlier in-situ precipitation measurements available as monthly data through the Nicholson database (Nicholson and Entekhabi, 1986) for the period 1954-1984 we selected the FEWS-Net data for the final model setup. A scatter plot of the annual precipitation sums against annual discharges reveals that the FEWSNet data lie in the same range with the Nicholson data and that the TRMM and ECMWF data are respectively too low and too high (Fig. 2b). The calibration of the model was carried out using FEWS-Net data but for comparison, additional model runs were completed with scaled ECMWF and TRMM data. The two datasets were multiplied with a constant so that the long term (2000-2009) precipitation sums over the Okavango catchment were the same as for FEWSNet data. This resulted in multipliers of 0.82 for ECMWF and 1.26 for TRMM data. 

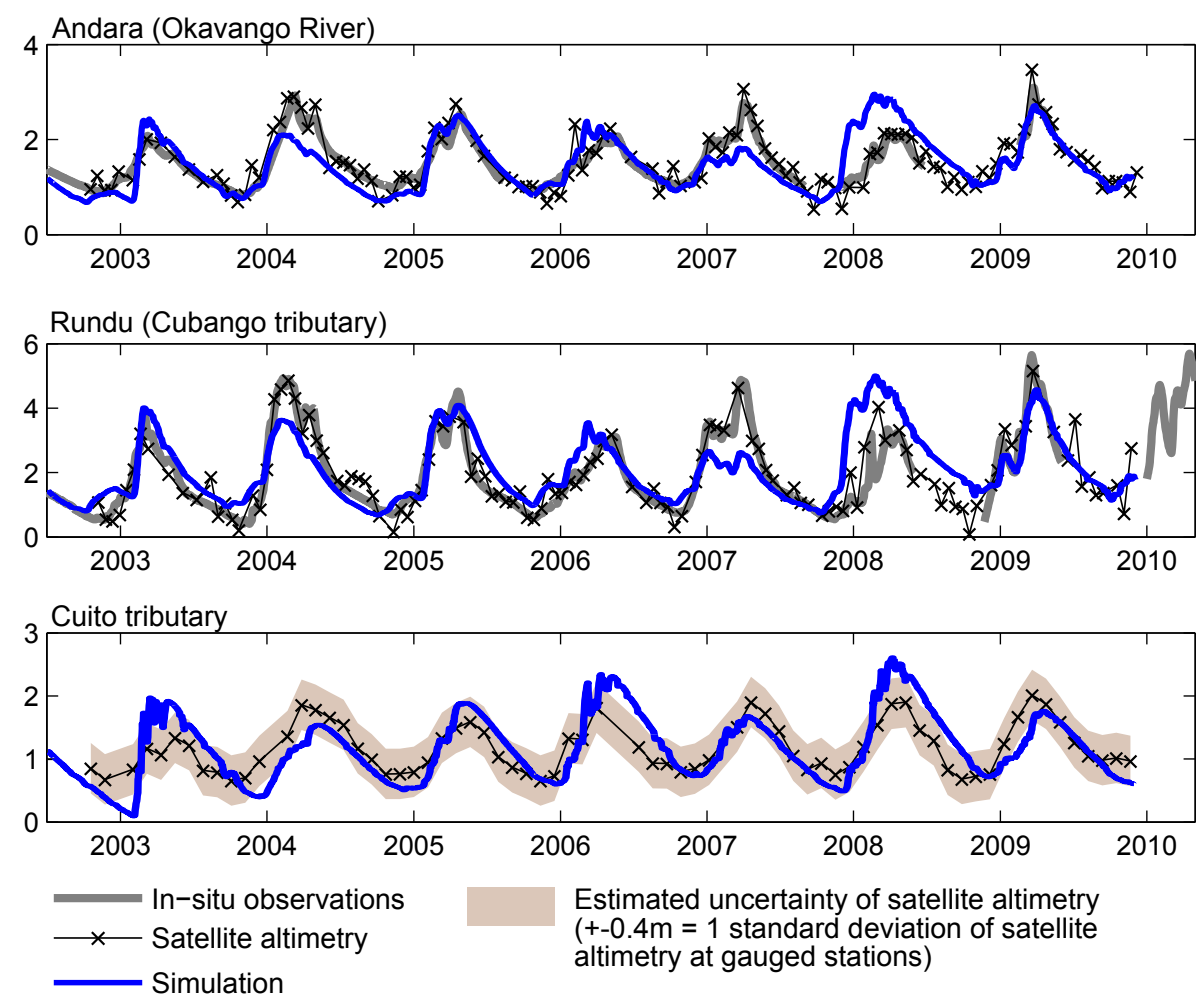

Fig. 3. Water levels at Rundu, Andara, and for the Cuito tributary. Simulations, remote sensed levels and in-situ observations (where available). For Rundu and Andara the satellite altimetry data is a combination from 2 virtual stations each (columns 2 and 4 in Table 1 ).

\subsection{Pre-processing of temperature data}

Because of the $6 \mathrm{~h}$ temporal resolution of the temperature data, the minimum and maximum daily temperatures are not necessarily recorded. We therefore compared ERA-Interim data with in-situ data of stations in the proximity of the Okavango catchment. We found that the daily minimum of the 6 hourly ERA-Interim data must on average be decreased by $2.7^{\circ} \mathrm{C}$ and the daily maximum value increased by $0.1^{\circ} \mathrm{C}$ to best reflect the in-situ station data. These corrections are applied to the ERA-Interim data of the Okavango catchment before they are used for evapotranspiration calculations in SWAT.

\subsection{Pre-processing of altimetry data}

Satellite altimetry has to our best knowledge never been applied to detect water level changes in streams as narrow as the Okavango and its tributaries. With approximately $150 \mathrm{~m}$ in width, the cross sections we analyse are at the detection limit for today's satellite based altimeters. Two of the virtual stations in the Okavango catchment coincide with in-situ river gauging stations. For each, a supplementary virtual station is located less than $20 \mathrm{~km}$ away from the gauging station. The accuracy of the remotely sensed levels can thus be assessed. The original RLA data contain all altimeter measurements in a corridor of $2 \mathrm{~km}$ width centred on the river. All measurements taken during one crossing of the corridor are then averaged to one value. We consider a subset of this data by selecting and averaging only those measurements in a corridor of $1 \mathrm{~km}$ width. Further, we applied an automatic correction for the slope of the river. This correction is necessary because measurements at one virtual station are not always taken at exactly the same location along the stream centreline because of variations in the satellite orbit. The orbit changes result in changes in retrieved water levels caused by different measurement positions. We correct for this by fitting a linear relationship between all measured elevations of a virtual station and their position along the river. The slope of the linear relationship is then removed from the data.

For all pre-processing methods we compute the root mean squared error (RMSE) relative to the in-situ measurements. Our results (Table 1) show that the width of the corridor has a considerable effect on the accuracy. While resulting in better accuracy, a narrower corridor reduces the number of available samplings only slightly. Combining measurements from two nearby virtual stations approximately doubles the number of observations but reduces the accuracy (see also Fig. 3). The effect of the channel slope correction differs between virtual stations. The virtual station at Rundu is located at a very regular and straight river section with low slope so that the correction brings little improvement. At the second 


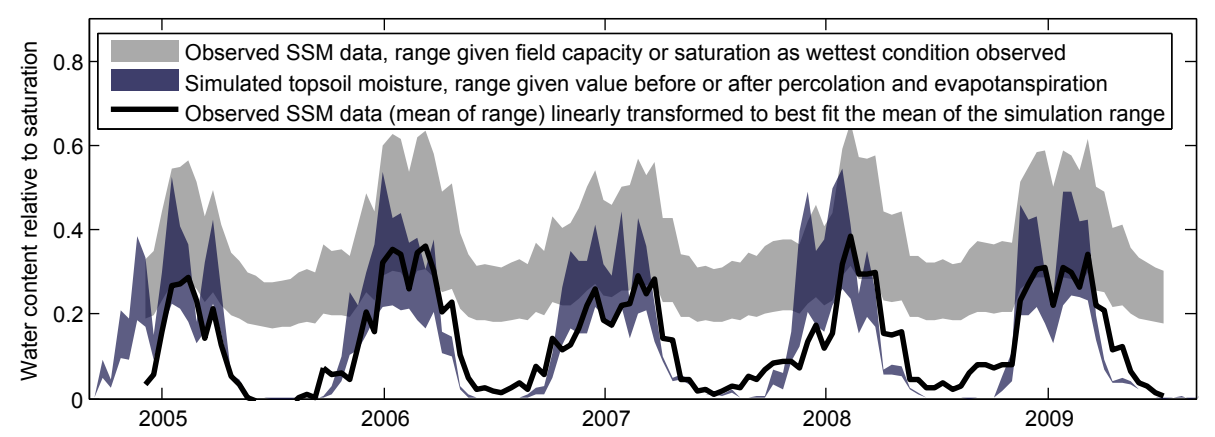

Fig. 4. Simulated top soil moisture ( $5 \mathrm{~cm}$ layer) using FEWS-Net rainfall estimates (RFE) and remotely sensed SSM. In this representation both moisture time series are averaged over the entire Okavango catchment and filtered with a moving average over 14 days.

Table 1. Root mean squared errors ( $\mathrm{m}$ ) of satellite based water levels relative to in-situ measurements at the stations Rundu and Andara using satellite altimetry data from one or two virtual stations, and, in brackets, number of samplings in the period 2003-2009. The benefit of taking a subset of the data from within a narrower corridor around the river and applying a slope correction is evaluated. (VS: virtual station, SC: slope correction.)

\begin{tabular}{lcccc}
\hline & Rundu & Rundu, 2 VS & Andara & Andara, 2 VS \\
\hline $2 \mathrm{~km}$ corridor & $0.46(67)$ & $0.56(129)$ & $0.28(72)$ & $0.51(141)$ \\
$2 \mathrm{~km}$ corridor + SC & $0.46(67)$ & $0.55(129)$ & $0.25(72)$ & $0.30(141)$ \\
$1 \mathrm{~km}$ corridor & $0.36(63)$ & $0.46(123)$ & $0.23(70)$ & $0.30(131)$ \\
$1 \mathrm{~km}$ corridor + SC & $0.34(63)$ & $0.40(123)$ & $0.21(70)$ & $0.24(131)$ \\
\hline
\end{tabular}

virtual station of the Andara location the river splits up in several nearby branches to flow down a series of minor topographic steps. The channel slope is higher there and the correction very beneficial, reducing the RMSE from 0.51 to $0.30 \mathrm{~m}$ for the combined stations with a $2 \mathrm{~km}$ corridor.

A virtual station is also located along the lowest part of the ungauged Cuito tributary (Fig. 1). Based on the findings for the two virtual stations with in-situ gauging we applied a $1 \mathrm{~km}$ corridor and the slope correction to the Cuito altimetry data. We assume that the Cuito data have a standard error similar to data at the gauged virtual stations, i.e. a RMSE of approximately $0.4 \mathrm{~m}$.

The simulated levels are scaled before being compared with the remotely sensed water levels. The 1-D stream flow routing component of SWAT accounts for one uniform stream cross section geometry per subbasin and in our large scale model setup these geometries must be representative for reaches of several tens of kilometres. In reality, however, stream geometries change within shorter distances and the stream width at gauging stations or virtual stations is thus not necessarily equal to the width assigned as representative for the corresponding subbasin.

\subsection{Pre-processing of SSM data}

Because the SSM data give moisture conditions relative to the wettest and driest conditions observed for each pixel, assumptions are necessary to transform the data into water content. We assume that the driest conditions observed correspond to the residual water content of the soil. Quantifying the residual water content accurately is difficult with the lack of knowledge for the catchments soils. We use the value of $6 \%$, which is given by Chesworth (2008) as a maximal value for sandy soils. The wettest conditions are equally difficult to quantify. We evaluate the SSM data using water content either at field capacity or at saturation as wettest conditions observed. In SWAT the water content at field capacity $\Theta_{\mathrm{fc}}$ is calculated based on other soil properties as

$\Theta_{\mathrm{fc}}=\Theta_{\mathrm{aw}}+0.4 \cdot \rho_{\mathrm{b}} \cdot m_{\mathrm{c}}$

where $\Theta_{\mathrm{aw}}$ is the plant available water content, $\rho_{\mathrm{b}}$ is the bulk density, and $m_{\mathrm{c}}$ is the fraction of clay material of the soil. The average field capacity for the Okavango catchment is 0.22 , the average porosity is 0.49 . The differences in soil water content resulting from the two possible assumptions for the wettest conditions are obviously large (Fig. 4).

Two important differences between the observed SSM data and the conceptional setup of the SWAT model make a direct comparison of simulated topsoil moisture with SSM data difficult:

- SWAT does not simulate the residual water content of soils. An exponential decay of soil evaporation is simulated when the soil water content falls below field capacity, allowing a complete drying of the soil because the evaporative flux approaches a non-zero value for infinitesimal small soil water contents.

- Precipitation events can occur shortly before or after the acquisitions of the SSM data, so that the measured data would respectively reflect wet or dry conditions relative to the average of the day. The simulation in SWAT operates with a constant daily sequence of precipitation - percolation - evapotranspiration. We therefore 
use daily simulation outputs of soil moisture immediately after precipitation and at the end of the sequence to get estimates of daily maximum and minimum soil moisture conditions. A simulation with sub-daily time steps would be necessary for a sound comparison of the SSM data with the simulation. But this is impossible for the Okavango catchment given the current precipitation data situation.

A direct comparison of simulated and observed surface soil moisture is thus presently not feasible in the case of the Okavango. A relative comparison is possible if we assume that the conceptual differences introduce biases that are constant over time. This is the case for the residual water content of the soil and for the water content at driest and wettest observed conditions. Also, the relative timing of measurements and precipitation events is expected to be on average the same at least when comparing e.g. wet seasons with each other. For the relative comparison we apply the linear transformation $f(x)=a \cdot x+b$ to the observed SSM data, were $a$ and $b$ are parameters constant in time and $x$ are the observed SSM data. The parameters are chosen so that the resulting time series $f(x)$ best fits the simulated values.

\subsection{Parameter sensitivity and calibration}

SWAT requires calibration of a number of parameters that must be estimated. To objectively combine the information contained in all in-situ and remotely sensed observational datasets we applied an automatic multi-objective calibration. Because of the non-linearities contained in complex hydrological models such as SWAT we further opted for a global search optimization algorithm. We applied the Shuffled Complex Evolution Metropolis algorithm (SCEM-UA) developed by Vrugt et al. (2003).

The parameters to be adjusted by the automatic calibration are defined through a sensitivity analysis of the manually calibrated model. The sensitivity of the model outputs for discharge, water levels, total storage variability and surface soil moisture are evaluated using composite scaled sensitivities (CSS, Hill and Tiedeman, 2007). The CSS of a simulated time series $f$ with $n$ elements to a parameter $p$ is defined as

$\operatorname{CSS}=\frac{1}{n} \cdot \sum_{i=1}^{n}\left(\left|\frac{\Delta f_{i} / f_{i}}{\Delta p / p}\right|\right)$

where $\Delta p$ is the change in parameter value and $\Delta f_{i}$ the change in the time series at time step $i$. SWAT parameters selected for the automatic calibration are: the groundwater baseflow recession constant (ALPHA_BF), the effective hydraulic conductivity of the channel alluvium (CH_K(2)), the soil evaporation compensation factor (ESCO), the plant available water content of the soil (SOL_AWC), the clay percentage of the soil (CLAY), the bulk density of the soil (SOL_BD), the correction factor for infiltration from rivers to
Table 2. Parameter values found by manual and automatic calibration.

\begin{tabular}{|c|c|c|c|}
\hline Parameter & $\begin{array}{l}\text { Manually } \\
\text { calibrated } \\
\text { value }\end{array}$ & $\begin{array}{l}\text { Range allowed } \\
\text { for at automatic } \\
\text { calibration }\end{array}$ & $\begin{array}{l}\text { Automatically } \\
\text { calibrated } \\
\text { value }\end{array}$ \\
\hline ALPHA_BF & 0.75 & [7.5E-3 75] & 0.45 \\
\hline ALPHA_BF ${ }_{b}$ & 0.01 & [1E-4 1] & 7.3E-3 \\
\hline ALPHA_BF & $1 \mathrm{E}-4$ & [1E-6 0.01$]$ & $3.9 \mathrm{E}-5$ \\
\hline CH_K $(2)_{\mathrm{a}}$ & 10 & {$\left[\begin{array}{lll}0.1 & 1000]\end{array}\right.$} & 49.2 \\
\hline $\mathrm{CH} \_\mathrm{K}(2)_{\mathrm{b}}$ & 60 & [0.6 6000] & 141.7 \\
\hline $\mathrm{ESCO}_{\mathrm{a}}$ & 0.25 & [2.5E-3 25] & 0.46 \\
\hline $\mathrm{ESCO}_{\mathrm{b}}$ & 0.8 & [8E-3 80] & 0.73 \\
\hline $\mathrm{ESCO}_{\mathrm{c}}$ & 0.1 & {$\left[\begin{array}{ll}1 \mathrm{E}-3 & 10\end{array}\right]$} & $5.0 \mathrm{E}-3$ \\
\hline MultsOL_AWC & 1 & {$\left[\begin{array}{ll}0.1 & 10\end{array}\right]$} & 3.38 \\
\hline Mult $_{\text {CLAY }}$ & 1 & {$\left[\begin{array}{ll}0.1 & 10\end{array}\right]$} & 1.056 \\
\hline MultsOL_BD & 1 & {$\left[\begin{array}{ll}0.1 & 10\end{array}\right]$} & 1.02 \\
\hline INFLFCT & 0.2 & {$\left[\begin{array}{lll}0.02 & 2\end{array}\right]$} & 0.24 \\
\hline $\mathrm{CH} \_\mathrm{N}(2)$ & 0.03 & [3E-4 3] & 1.13 \\
\hline Mult $_{\text {SoilFactor }}$ & 1 & {$\left[\begin{array}{ll}0.1 & 10\end{array}\right]$} & 0.60 \\
\hline
\end{tabular}

the shallow aquifer (INFLFCT), Manning's roughness coefficient for channels ( $\mathrm{CH}_{-} \mathrm{N}(2)$ ), and the multiplier to the thickness of soil layers 2 and 3 (SoilFactor; the thickness of the top soil layer is kept constant for consistency with the SSM data). The first three parameters can vary independently for different regions of the catchment. The parameters describing soil characteristics are calibrated using multipliers so that the initial spatial variability resulting from soil type maps is maintained. Bounds of the intervals allowed in parameter calibration are reported in Table 2.

The objective function to be minimized by the calibration minimizes the differences between simulated and observed time series of:

- Discharge at Andara and Rundu (MARE).

- Stages at Andara, Rundu and for the Cuito tributary (MARE).

- Flow regime of the Cuito tributary, where the observed regime is derived by subtracting discharge at Rundu from discharge at Andara (WMRSE).

- Flow regime at Mucundi, where the observed regime is based on historical data of the period from 1961 to 1974 (WMRSE). The comparison is justified because flow regimes at the downstream station of Rundu are very similar for the historical and the simulation period.

- Catchment total water storage (MARE).

- Surface soil moisture, where the goodness-of-fit is computed after a linear transformation that best relates observed and simulated data (WMAE). 


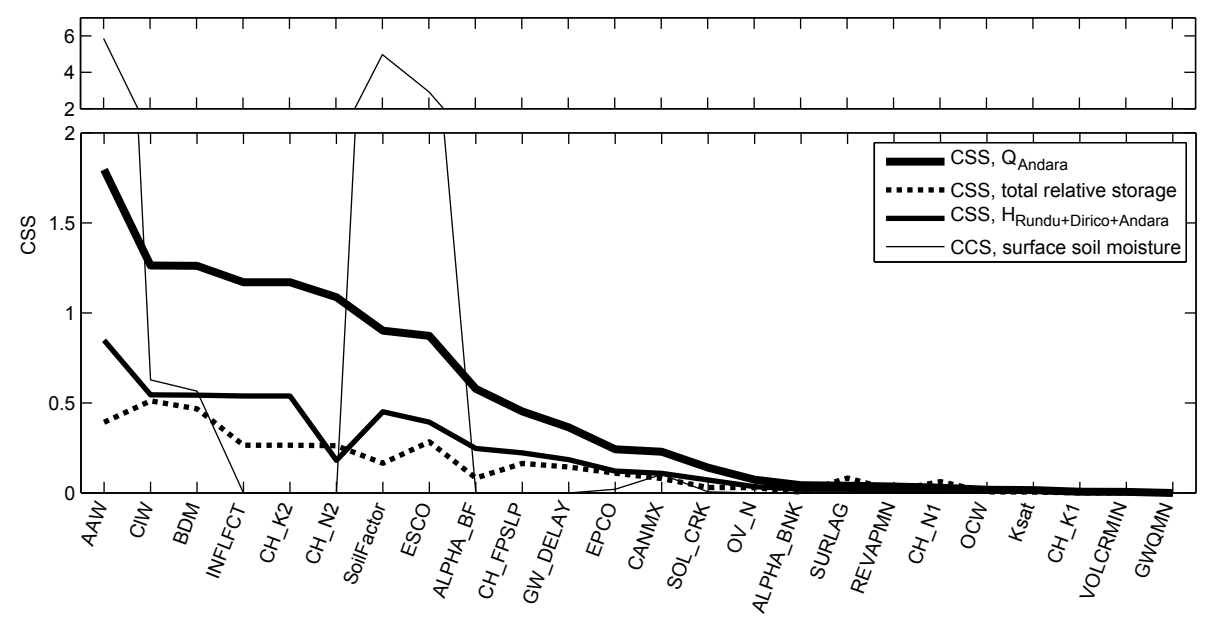

Fig. 5. Composite scaled sensitivities (CSS) of the main model outputs with respect to different model parameters. The parameters are sorted in order of decreasing sensitivity with respect to discharge at Andara.

The acronyms in brackets stand for the goodness-of-fit measures used. MARE is the mean absolute relative error. WRMSE is the weighted root mean squared error. WMAE is the weighted mean absolute error. The weighting for the latter two is achieved through division by the standard deviation of the observed data. The final objective function consists of the sum of the 9 goodness-of-fit measures. The combination of 9 objectives involves that a better fit for one objective (e.g. discharge at Andara) could be achieved when not considering the other objectives. However, the model calibrated for the sum of multiple objectives represents the best compromise for fitting all observed data. It is therefore expected to achieve a better physical description of the catchment than a model calibrated only for one objective.

We do not split the period with available input and validation data (2000-2009) into distinct calibration and validation periods. Given that our model is developed to evaluate the impact of future land use change, a proper validation would require a "differential split-sample test" (Klemes, 1986), in which calibration and validation periods differ in their land use. Such periods are however not available. A simple "split sample" test (Klemes, 1986) would be of limited relevance for our study and decrease the calibration potential.

\section{Results}

Through the sensitivity analysis we find that discharge and water levels are more sensitive than the water storage and that the topsoil water content has little sensitivity (Fig. 5). The higher sensitivity of discharge can be explained by the nonlinearity relating percolation and river runoff in a catchment. River runoff represents only a small fraction of the precipitation inputs (approx. $6 \%$ for the Okavango at Andara) so that a small relative change in evapotranspiration can result in a large relative change in runoff. By contrast, a small change in evapotranspiration induces only a small change of total storage. The only two parameters to which the total storage variation is more sensitive than the other model outputs are SURLAG and CH_N1. Both are related to the delay of surface runoff.

The reduced sensitivity of the topsoil water content is due to the small volume of water that can be stored in this thin layer and the sequential order of computation in SWAT. Only few parameters have an influence on the topsoil water content, these are the parameters related to canopy interception and to the topsoil layer itself. Soil moisture is extremely sensitive to some of these parameters: these are AAW controlling the water retention capacity, SoilFactor a multiplier to the soil thickness, and ESCO controlling the amount of soil evaporative demand that can be taken from lower soil layers.

The ranking order of the parameters in terms of sensitivity shows similar trends for simulated runoff, stages and storage but has some noteworthy exceptions. ALPHA_BF, the base flow recession constant controlling changes in groundwater flow to the streams in response to changes in recharge, ranks higher for discharge than for storage variations. $\mathrm{CH}$ N2, the channel Manning's roughness coefficient ranks much lower for water levels than for discharge. These differences in sensitivity show that the observational data of discharge, water levels and total storage can be used to calibrate and validate different parts of the hydrological model.

Values of the most sensitive parameters defined through the manual and automatic calibrations are listed in Table 2. The two headwater regions have very different flow regimes that result from different geologies. Thicker layers of Kalahari Sands in the eastern headwaters lead to a more baseflowdominated regime. An earlier and much higher flood peak is observed for the western headwaters. In terms of model parameters, this resulted in a much lower baseflow recession 


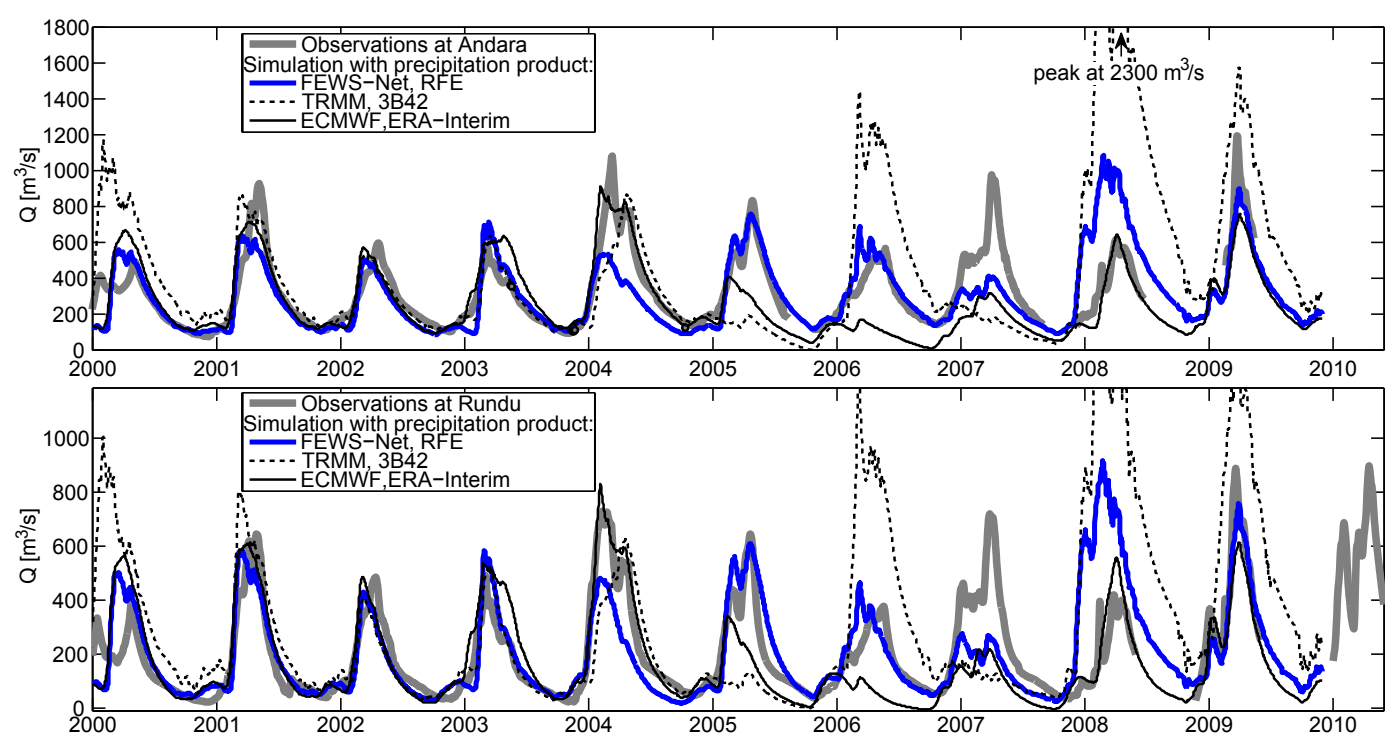

Fig. 6. Observed and simulated discharge at Rundu and Andara. Simulations were forced with the three different precipitation products (FEWS-Net, TRMM, ECMWF).

constant value for the eastern headwaters (ALPHA_BF ${ }_{b}$ ) than for the western headwaters (ALPHA_BF $F_{a}$ ) during both the manual an automatic calibration.

An interesting finding is that the three precipitation products used result in very different runoff simulations even after scaling the precipitation products to the same long term mean (Fig. 6, Table 3). The FEWS-Net and ECMWF data result in a far better fit of the observed discharge than the TRMM dataset as shown by evaluations of the Nash-Sutcliffe model efficiency coefficient (NSC, Nash and Sutcliffe, 1970). The NSC of these two best performing precipitation datasets is very simillar when computed over the entire 10 -year simulation period but the products result in very different qualities of fit for inividual years. If the high flow period of 2008 is excluded for the NSC computation of the simulation with FEWS-Net data, the NSC value improves from 0.37 to 0.63 . Whereas the same year of 2008 is well simulated with ECMWF data. The absolute value of the NSC should be assessed with care because of this high sensitivity to strong deviations in individual years. The model's capability of simulating accurate discharge rates at the catchment outlet is limited using any of the three precipitation products. The typical multiple flow peaks per year are captured but their amplitude is often wrong.

The simulated water levels at Rundu and Andara, when corrected for the differences between subbasin representative and gauging station channel width (Sect. 2.7), fit the in-situ observations well in terms of timing of flood peaks (Fig. 3). The amplitudes are often less well reproduced, which is also true for the simulated discharges. The comparison of simulated and remotely sensed water levels at Cuito, where the latter is the only observational data source, is satisfactory.
Table 3. Nash-Sutcliffe model efficiency on simulated discharge at Andara for the period 2000-2009. The precipitation products are scaled to have identical average catchment precipitation over the period.

\begin{tabular}{lrr}
\hline $\begin{array}{l}\text { Precipitation } \\
\text { product }\end{array}$ & $\begin{array}{r}\text { Including 2008 } \\
\text { high flow period }\end{array}$ & $\begin{array}{r}\text { Excluding 2008 } \\
\text { high flow period }\end{array}$ \\
\hline FEWS-Net, RFE & 0.37 & 0.63 \\
TRMM, 3B42 & -3.0 & -0.64 \\
ECMWF, ERA-Interim & 0.38 & 0.37 \\
\hline
\end{tabular}

Simulated levels fall mostly within one standard deviation (RMSE at the stations with in-situ gauging) of the remote observations. Over- or underestimations of the maximal flood levels occur in the same years as for the Cubango tributary.

Despite the model's limitations in simulating daily discharges, the flow regimes of the Okavango River and its two very different tributaries are satisfactorily simulated (Fig. 7). We note that the rising limbs of the simulated hydrographs are a little too steep and that the annual maximal flows are therefore too early. This feature could not be corrected during the calibration of the model.

The comparison of simulated and observed surface soil moisture shows notable disagreements. This is due to the compatibility limitations between SWAT and the SSM product detailed in Sect. 2.8. Soil moisture during the dry season is simulated as close to zero by the model but is of approximately 20 to $30 \%$ of saturation in the SSM data (Fig. 4). The relative comparison, using scaled SSM data, reveals that there is good agreement of the onset of wet and dry seasons 

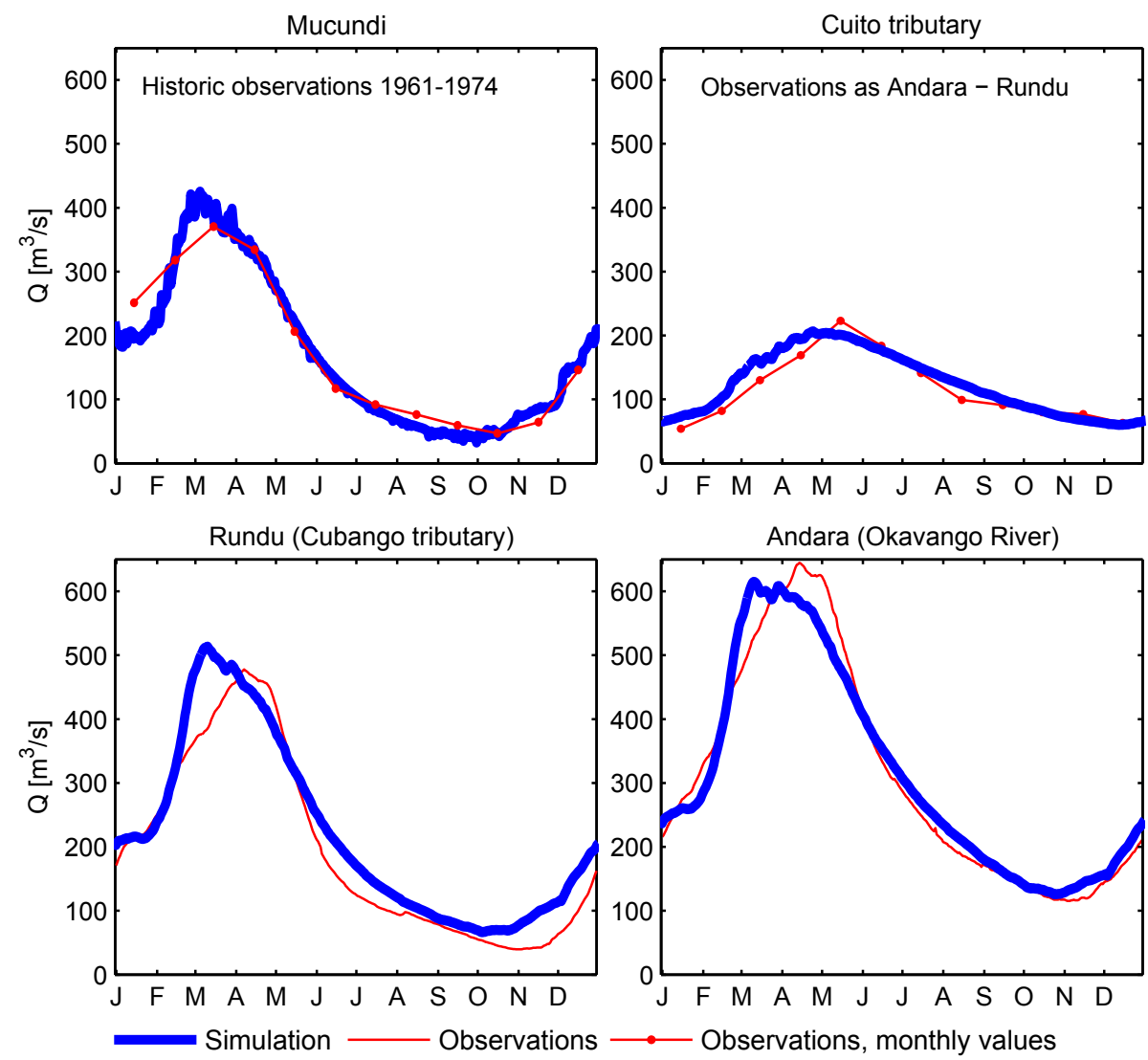

Fig. 7. Simulated and observed flow regimes of the Okavango River and its two main tributaries. Station locations are indicated in Fig. 1.

and that within the wet period the timing of individual rises and falls of the soil water content is often consistent. Two important differences are identified. The SSM dataset shows a slow increase at the end of the dry season before the more pronounced increase at the beginning of the wet season. The simulation misses this first increase. For the year 2008 the simulated soil moisture of the first half of the wet season is largely higher than the observed one. Both of these differences have their analogy in the simulated catchment outflow. The simulated discharges tend to increase too late after the onset of the wet season and the high flows of 2008 are strongly over-predicted by the simulation. The overprediction of discharge in 2008 is most likely due to an overestimation of the FEWS-Net rainfall estimate for that year.

On the interannual time scale an agreement of the ENVISAT surface soil moisture with the total water storage from GRACE is observed. The driest dry season is the one of 2005 in both datasets. In the following years the minimal values of each dry season are higher again in both observational datasets.

Simulated water storage variations are derived from the 10 reservoirs considered in SWAT:

- Snow storage (irrelevant in our case)
- Canopy interception

- Surface runoff lag

- Lateral flow runoff lag

- Soil storage

- Vadose zone percolation lag

- Shallow aquifer storage

- Deep aquifer storage (inactivated in our case)

- River storage

- River bank storage.

We find that the lion's share $(98.7 \%)$ of the simulated total storage variations result from the soil-, vadose zone-, shallow aquifer-, and surface runoff lag storages (Fig. 8). The total water storage variations derived from GRACE data have similar dynamics but generally higher annual amplitudes. The under-estimation of water storage amplitudes in the simulation is often an indication for an under-estimation of the precipitation input. In the 2004 and 2007 flood seasons for example, both discharge and total water storage are consistently under-predicted by the model. Overall, there is a deficit of 


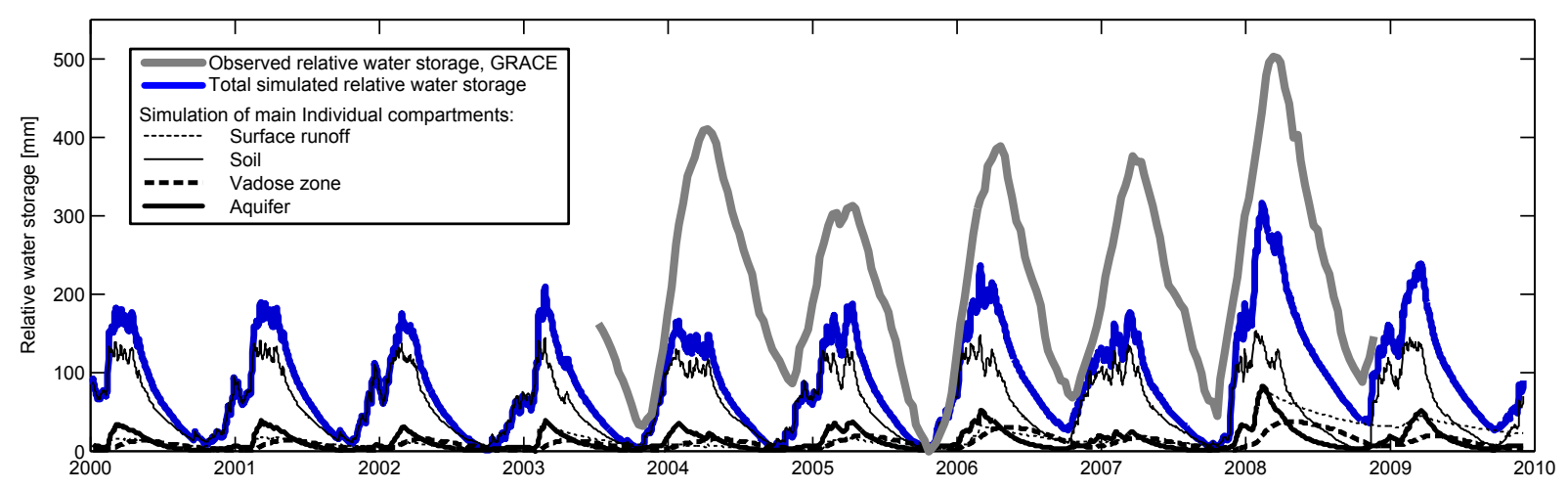

Fig. 8. Storages variations within the Okavango catchment derived from GRACE and simulated with the SWAT model. The 4 storage compartments shown in the plot account for $98.7 \%$ of the simulated total water storage variation. (The minimum value of all curves is set to zero.)

water in the simulation in these years, which is not caused by too high river outflows. The deficit could be due to either too high evapotranspiration rates or too low precipitation inputs. Because of the under-estimation of the storage amplitude, the likely reason for the insufficient fit in 2004 and 2007 is underestimation of the precipitation input. The simulation of the 2005 flood season therefore starts with too low total water storage, but the simulated increase is of the same amplitude as the increase in the GRACE data. Simulated and observed discharges are also consistent in 2005. For 2006 we observe a slight over-prediction of discharge whereas the total storage amplitude is strongly under-estimated. Similar to 2005, the simulation of the 2008 flood season starts with too low total water storage, because of under-estimated storage in the previous year. Despite a strong over-estimation of runoff in 2008 , the storage amplitude is not over-estimated. This indicates that the excess runoff may be due to overland flow processes.

An increasing trend might be visually identified in the relative water storage derived from GRACE data. This impression is however caused only by the wetter year 2008. A linear fit of the GRACE data from 20 October 2003 to 20 October 2008 (20 October being the driest time for both years) has indeed a slope of $+13.5 \mathrm{~mm} \mathrm{yr}^{-1}$ but a linear fit until 20 October 2007 has a slope of $-9.1 \mathrm{~mm} \mathrm{yr}^{-1}$. The simulation shows similar behaviour with slopes of respectively +12.3 and $-3.1 \mathrm{~mm} \mathrm{yr}^{-1}$ for linear fits over the same periods. Our data do therefore not show any trends in the relative water storage of the catchment.

\section{Discussion}

Given the poor performance of the model to simulate daily discharges, an application for flow forecasting is not possible yet. We expect the main reason for this to be erroneous precipitation amounts caused by lack of in-situ precipitation measurements. The very large differences between the three applied precipitation products indicate that accurate remote measurements of precipitation over the Okavango catchment are currently infeasible. The runoff-generating part of the catchment does not include any operational precipitation gauge and it is questionable if remote sensing products can at all provide accurate quantitative precipitation amounts for ungauged basins. The performance of the precipitation products is difficult to assess because over ungauged catchments per se no in-situ measurements are available and in gauged basins the data are already used for the generation of the precipitation product.

The relatively good fit of the flow regimes suggests that the model is able to simulate the proper rainfall-runoff characteristics of the catchment. The model can thus be used for long term scenario analyses. It will be applied to study the impact of land use changes through intensified agriculture on catchment outflow.

The misfit of the total water storage amplitude simulated with SWAT relative to the GRACE mascon observations may be to a certain degree attributable to errors in the mason processing. Because of the lack of alternative observational data on total water storage variations the accuracy of the mascon solutions cannot be verified.

The combination of multiple independent observational datasets improves the parametrization of the hydrological model. Equifinality still cannot be excluded in our model because of the large number of parameters resulting from the semi-distributed modelling approach. When applying the hydrological model for scenario investigations, this source of uncertainty must be kept in mind.

It is remarkable that consistent time series of water levels could be extracted for the tributaries of the Okavango River approximately $150 \mathrm{~m}$ in width. Previously altimetry data had been used only for lakes and major river systems such as the Amazon. For relatively narrow rivers the altimetry data might not result in good results when processed 
automatically but with manual selections of the individual target points based on knowledge of the water body position good results can be achieved. These results are very promising, also because future satellite missions (Sentinel3, SWOT) will operate at higher spatial resolutions thereby definitely expanding the number of river basins for which satellite altimetry is a valuable data source.

\section{Conclusions}

We have set up a hydrological model for the poorly gauged Okavango catchment using remotely sensed data with nearglobal coverage and data from few in-situ stream gauges. Simulated discharges, stages, surface soil moisture and storage are found to have different model parameters to which they are most sensitive. The remotely sensed datasets available for model calibration can thus be used to condition different parameters and equifinality of the parameter set can be reduced.

The model is calibrated against all available remotely sensed and in-situ observations following an automatic multi-objective procedure and deploying a global search over the parameter space. An objective combination of the diverse available data is thus achieved.

The three employed precipitation products exhibit very large differences in annual sums of precipitation estimates for the catchment. Consequently they result in very different runoff simulations. We found that for our period of investigation (2000-2009) and the Okavango catchment, FEWS-Net RFE data perform better than TRMM 3B42 and ECMWF ERA-Interim data. Discrepancy in specific periods between simulated and observed surface soil moisture as well as total storage allowed identifying likely errors in the precipitation data. The model's accuracy in simulating catchment outflow is largely diminished by the errors in the precipitation data.

Satellite altimetry was used to retrieve water level fluctuations at three locations in the catchment for channels approximately $150 \mathrm{~m}$ in width. Comparisons with in-situ observations at two of these locations revealed a root mean squared error of the remotely sensed levels of $0.4 \mathrm{~m}$ or below.

Acknowledgements. We acknowledge the Department of Water Affairs of the government of Namibia and the Department of Water Affairs of the government of Botswana for providing river stage and discharge data. Altimetry data was processed under ESA contract ESRIN/RFQ/3-12093/07/I-LG (EAPRS, De Montfort University; CEG, Newcastle University; DTU Environment, Technical University of Denmark). This work was funded by the Swiss National Science Foundation (PBEZP2-127760) and hosted at the Department of Environmental Engineering, Technical University of Denmark.

Edited by: N. Romano

\section{References}

Adler, R., Braun, S., Stocker, E., and Marius, J.: Tropical Rainfall Measuring Mission, TRMM, Senior Review Proposal, Tech. rep., Laboratory for Atmospheres, NASA Goddard Space Flight Centre, 2007.

Andersson, J.: Land cover change in the Okavango River Basin, Master thesis, 2006.

Arnold, J. G., Srinivasan, R., Muttiah, R. S., and Williams, J. R.: Large area hydrologic modeling and assessment - Part 1: Model development, J. Am. Water Resour. Assoc., 34, 73-89, 1998.

Awange, J. L., Fleming, K. M., Kuhn, M., Featherstone, W. E., Heck, B., and Anjasmara, I.: On the suitability of the 4 degrees $\times 4$ degrees GRACE mascon solutions for remote sensing Australian hydrology, Remote Sens. Environ., 115, 864-875, 2011.

Bartsch, A.: SHARE - soil moisture monitoring in Africa, GEOconnexion International, 7, 46-47, 2008.

Bartsch, A., Doubkova, M., and Wolski, P.: River flow and wetland monitoring with Envisat ASAR global mode in the Okavango basin and delta, Proceedings of the Second IASTED Africa Conference, 8-10 September 2008 Gaborone, Botswana, 2008.

Becker, M., Llovel, W., Cazenave, A., Guntner, A., and Cretaux, J. F.: Recent hydrological behavior of the East African great lakes region inferred from GRACE, satellite altimetry and rainfall observations, Comptes Rendus Geoscience, 342, 223-233, 2010.

Berrisford, P., Dee, D. P. K. F., Fuentes, M., Kållberg, P., Kobayashi, S., and Uppala, S. M.: The ERA-Interim Archive, Tech. rep., ERA Report Series No. 1, available at: www.ecmwf. int/publications, last access: 15 May 2010, ECMWF, Reading, UK, 2009.

Berry, P. A. M., Garlick, J. D., Freeman, J. A., and Mathers, E. L.: Global inland water monitoring from multi-mission altimetry, Geophys. Res. Lett., 32, L16401, doi:10.1029/2005GL022814, 2005.

Birkett, C. M. and Beckley, B.: Investigating the Performance of the Jason-2/OSTM Radar Altimeter over Lakes and Reservoirs, Mar. Geod., 33, 204-238, 2010.

Birkinshaw, S. J., O’Donnell, G. M., Moore, P., Kilsby, C. G., Fowler, H. J., and Berry, P. A. M.: Using satellite altimetry data to augment flow estimation techniques on the Mekong River, Hydrol. Process., 24, 3811-3825, 2010.

Calmant, S., Seyler, F., and Cretaux, J. F.: Monitoring Continental Surface Waters by Satellite Altimetry, Surv. Geophys., 29, 247269, 2008.

Chen, J. L., Wilson, C. R., and Tapley, B. D.: The 2009 exceptional Amazon flood and interannual terrestrial water storage change observed by GRACE, Water Resour. Res., 46, W12526, doi:10.1029/2010WR009383, 2010.

Chesworth, W.: Encyclopedia of Soil Science, Encyclopedia of Earth Sciences Series, Springer, Dordrecht, The Netherlands, 2008.

Coe, M. T., Costa, M. H., and Howard, E. A.: Simulating the surface waters of the Amazon River basin: impacts of new river geomorphic and flow parameterizations, Hydrol. Process., 22, 2542-2553, 2008. 
Crow, W. T. and Ryu, D.: A new data assimilation approach for improving runoff prediction using remotely-sensed soil moisture retrievals, Hydrol. Earth Syst. Sci., 13, 1-16, doi:10.5194/hess13-1-2009, 2009.

FAO: Digital soil map of the world and derived soil properties [CDROM], Version 3.5, Land and Water Digital Media Series Number 1, Rome, Italy, 1995.

Farr, T. G., Rosen, P. A., Caro, E., Crippen, R., Duren, R., Hensley, S., Kobrick, M., Paller, M., Rodriguez, E., Roth, L., Seal, D., Shaffer, S., Shimada, J., Umland, J., Werner, M., Oskin, M., Burbank, D., and Alsdorf, D.: The shuttle radar topography mission, Rev. Geophys., 45, RG2004, doi:10.1029/2005RG000183, 2007.

Fekete, B. M. and Vörösmarty, C. J.: The current status of global river discharge monitoring and potential new technologies complementing traditional discharge measurements, Predictions in Ungauged Basins: PUB Kick-off, Proceedings of the PUB Kickoff meeting held in Brasilia, 20-22 November 2002, IAHS Publ. 309, 2007.

Folwell, S. and Farqhuarson, F.: The impacts of climate change on water resources in the Okavango basin, in: Climate Variability and Change - Hydrological Impacts, edited by: Demuth, S., Gustard, A., Planos, E., Scatena, F., and Servat, E., folwell, Sonja Farqhuarson, Frank 5th FRIEND World Conference Nov 2006 Havana, CUBA, vol. 308, Iahs Publication, 382-388, 2006.

Herman, A., Kumar, V. B., Arkin, P. A., and Kousky, J. V.: Objectively determined 10-day African rainfall estimates created for famine early warning systems, Int. J. Remote Sens., 18, 21472159, 1997.

Hill, M. C. and Tiedeman, C. R.: Effective Groundwater Model Calibration: With Analysis of Data, Sensitivities, Predictions, and Uncertainty, Wiley, 2007.

Hughes, D. A., Andersson, L., Wilk, J., and Savenije, H. H. G.: Regional calibration of the Pitman model for the Okavango River, J. Hydrol., 331, 30-42, 2006.

Hughes, D. A., Kingston, D. G., and Todd, M. C.: Uncertainty in water resources availability in the Okavango River basin as a result of climate change, Hydrol. Earth Syst. Sci., 15, 931-941, doi:10.5194/hess-15-931-2011, 2011.

Jones, P. D. and Moberg, A.: Hemispheric and large-scale surface air temperature variations: An extensive revision and an update to 2001, J. Climate, 16, 206-223, 2003.

Junk, W. J., Brown, M., Campbell, I. C., Finlayson, M., Gopal, B., Ramberg, L., and Warner, B. G.: The comparative biodiversity of seven globally important wetlands: a synthesis, Aquat. Sci., 68, 400-414, 2006.

Kgathi, D. L., Kniveton, D., Ringrose, S., Turton, A. R., Vanderpost, C. H. M., Lundqvist, J., and Seely, M.: The Okavango; a river supporting its people, environment and economic development, J. Hydrol., 331, 3-17, 2006.

Klemes, V.: Operational testing of hydrological simulation-models, Hydrolog. Sci. J. - Journal Des Sciences Hydrologiques, 31, 1324, 1986.

Kouraev, A. V., Zakharova, E. A., Samain, O., Mognard, N. M., and Cazenave, A.: Ob' river discharge from TOPEX/Poseidon satellite altimetry (1992-2002), Remote Sens. Environ., 93, 238$245,2004$.
Krogh, P. E.: Large Scale Hydrological Model Calibration with remote sensing data from GRACE, PhD dissertation, Technical University of Denmark, Ph.D. thesis, 2011.

Landerer, F. W., Dickey, J. O., and Guntner, A.: Terrestrial water budget of the Eurasian pan-Arctic from GRACE satellite measurements during 2003-2009, J. Geophys. Res.-Atmos., 115, D23115, doi:10.1029/2010JD014584, 2010.

Leiriao, S., He, X., Christiansen, L., Andersen, O. B., and BauerGottwein, P.: Calculation of the temporal gravity variation from spatially variable water storage change in soils and aquifers, J. Hydrol., 365, 302-309, 2009.

Lo, M. H., Famiglietti, J. S., Yeh, P. J. F., and Syed, T. H.: Improving parameter estimation and water table depth simulation in a land surface model using GRACE water storage and estimated base flow data, Water Resour. Res., 46, W05517, doi:10.1029/2009WR007855, 2010.

Luthcke, S. B., Arendt, A. A., Rowlands, D. D., McCarthy, J. J., and Larsen, C. F.: Recent glacier mass changes in the Gulf of Alaska region from GRACE mascon solutions, J. Glaciol., 54, 767-777, 2008.

Meier, P., Frömelt, A., and Kinzelbach, W.: Hydrological real-time modelling in the Zambezi river basin using satellite-based soil moisture and rainfall data, Hydrol. Earth Syst. Sci., 15, 9991008, doi:10.5194/hess-15-999-2011, 2011.

Mendelson, J. and el Obeid, S.: The flow of a lifeline, Struik Publishers, Cape Town, South Africa, 2004.

Milzow, C., Kgotlhang, L., Bauer-Gottwein, P., Meier, P., and Kinzelbach, W.: Regional review: The hydrology of the Okavango Delta, Botswana - processes, data and modelling, Hydrogeol. J., 17, 1297-1328, 2009a.

Milzow, C., Kgotlhang, L., Kinzelbach, W., Meier, P., and BauerGottwein, P.: The role of remote sensing in hydrological modelling of the Okavango Delta, Botswana, J. Environ. Manage., 90, 2252-2260, 2009b.

Milzow, C., Burg, V., and Kinzelbach, W.: Estimating future ecoregion distributions within the Okavango Delta Wetlands based on hydrological simulations and future climate and development scenarios, J. Hydrol., 381, 89-100, 2010.

Mmopelwa, G. and Blignaut, J. N.: The Okavango Delta: The value of tourism, South Afr. J. Econ. Manage. Sci., 9, 113-127, 2006.

Moiwo, J. P., Yang, Y. H., Li, H. L., Han, S. M., and Hu, Y. K.: Comparison of GRACE with in situ hydrological measurement data shows storage depletion in Hai River basin, Northern China, Water Sa, 35, 663-670, 2009.

Nash, J. E. and Sutcliffe, J. V.: River flow forecasting through conceptual models part I - A discussion of principles, J. Hydrol., 10, 282-290, 1970.

Neitsch, S. L., Arnold, J. R., Kiniry, J. R., and Williams, J. R.: Soil and Water Assessment Tool, Theoretical Documentation, Tech. rep., Grassland, soil and water research laboratory, Agricultural research service, Temple, Texas, US, 2005.

Nicholson, S. E. and Entekhabi, D.: The quasi-periodic behavior of rainfall variability in Africa and its relationship to the southern ocillation, Archives for Meteorology Geophysics and Bioclimatology Series a - Meteorology and Atmospheric Physics, 34, 311-348, 1986. 
Parajka, J., Naeimi, V., Blöschl, G., Wagner, W., Merz, R., and Scipal, K.: Assimilating scatterometer soil moisture data into conceptual hydrologic models at the regional scale, Hydrol. Earth Syst. Sci., 10, 353-368, doi:10.5194/hess-10-353-2006, 2006

Peterson, T. C. and Vose, R. S.: An overview of the global historical climatology network temperature database, B. Am. Meteorol. Soc., 78, 2837-2849, 1997.

Pfeffer, J., Boucher, M., Hinderer, J., Favreau, G., Boy, J. P., de Linage, C., Cappelaere, B., Luck, B., Oi, M., and Le Moigne, N.: Local and global hydrological contributions to time-variable gravity in Southwest Niger, Geophys. J. Int., 184, 661-672, 2011.

RAISON: Sharing Water: Towards a Transboundary Consensus on the Management of the Okavango/Cubango River Basin. Natural Heritage Institute, San Francisco, http://www.sharing-water.net, last access: November 2010, Tech. rep., 2004.

Rallison, R. E. and Miller, N.: Past, present, and future SCS runoff procedure. Proceedings of the International Symposium on Rainfall-Runoff Modelling, 18-21 May 1981, Mississippi, USA, Water Resources Publications, 1981.

Ramberg, L., Hancock, P., Lindholm, M., Meyer, T., Ringrose, S., Sliva, J., Van As, J., and VanderPost, C.: Species diversity of the Okavango Delta, Botswana, Aquat. Sci., 68, 310-337, 2006.

Rowlands, D. D., Luthcke, S. B., McCarthy, J. J., Klosko, S. M., Chinn, D. S., Lemoine, F. G., Boy, J. P., and Sabaka, T. J.: Global mass flux solutions from GRACE: A comparison of parameter estimation strategies-Mass concentrations versus Stokes coefficients, J. Geophys. Res.-Solid, 115, B01403, doi:10.1029/2009JB006546, 2010.

Sarmiento, S. E. and Khan, S. D.: Spatial-Temporal Variability of Great Slave Lake Levels From Satellite Altimetry, IEEE Geosci. Remote Sens. Lett., 7, 426-429, 2010.
Schuol, J., Abbaspour, K. C., Yang, H., Srinivasan, R., and Zehnder, A. J. B.: Modeling blue and green water availability in Africa, Water Resour. Res., 44, W07406, doi:10.1029/2007WR006609, 2008.

Scipal, K., Scheffler, C., and Wagner, W.: Soil moisture-runoff relation at the catchment scale as observed with coarse resolution microwave remote sensing, Hydrol. Earth Syst. Sci., 9, 173-183, doi:10.5194/hess-9-173-2005, 2005.

Tang, Q. H., Gao, H. L., Lu, H., and Lettenmaier, D. P.: Remote sensing: hydrology, Progr. Phys. Geogr., 33, 490-509, 2009.

Tapley, B. D., Bettadpur, S., Watkins, M., and Reigber, C.: The gravity recovery and climate experiment: Mission overview and early results, Geophys. Res. Lett., 31, L09607, doi:10.1029/2004GL019920, 2004.

USGS: Global Land Cover Characterization, GLCC, http:// edcsns17.cr.usgs.gov/glcc/, (last access: August 2010), 2008.

Vrugt, J. A., Gupta, H. V., Bouten, W., and Sorooshian, S.: A Shuffled Complex Evolution Metropolis algorithm for optimization and uncertainty assessment of hydrologic model parameters, Water Resour. Res., 39, 1201, doi:10.1029/2002WR001642, 2003.

Wagner, W., Pathe, C., Sabel, D., Bartsch, A., Kuenzer, C., and Scipal, K.: Experimental $1 \mathrm{~km}$ soil moisture products from ENVISAT ASAR for Southern Africa, in: Proceedings of the ENVISAT Symposium 2007, 23-27 April 2007, ESA SP-636, Montreux, Switzerland, 2007.

Winchell, M., Srinivasan, R., Di Luzio, M., and Arnold, J. G.: ArcSWAT interface for SWAT2005 - Users guide, Blackland Research Center, Texas Agricultural Experiment Station and Grassland, Soil and Water Research Laboratory, USDA Agricultural Research Service, Tech. rep., Temple, Texas, 2007. 